Bioscientia Medicina: Journal of Biomedicine \& Translational Research

Journal Homepage: www.bioscmed.com

\title{
Clinical Correlations Delirium and other Comorbid in Elderly with COVID-19 Infection
}

\section{Khoirun Mukhsinin Putra1 ${ }^{\star}$, Nur Riviati², Djunaidi AR ${ }^{2}$}

${ }^{1}$ Department of Internal Medicine, Faculty of Medicine, Universitas Sriwijaya, Palembang, Indonesia

${ }^{2}$ Division of Geriatric, Departement of Internal Medicine, Faculty of Medicine, Universitas Sriwijaya, Palembang, Indonesia

\section{A R T I C L E I N F O}

Keywords:

Delirium

multiple comorbid

Elderly

Covid-19 infection

\section{*Corresponding author:}

Khoirun Mukhsinin Putra

\section{E-mail address:}

\section{khoirunmputra@gmail.com}

All authors have reviewed and approved the final version of the manuscript.

https://doi.org/10.32539/bsm.v5i10.361

\begin{abstract}
A B S T R A C T
Background. Delirium is a common condition in geriatric patients. One of the trigger factors for this condition is an infection, such as COVID-19 infection. Elderly with COVID-19 show atypical symptoms such as delirium. Elderly patients with COVID19 who present with delirium, either as a primary symptom or showing symptoms or signs, have a poor prognosis. This study were aimed to presents covid-19 elderly patient with comorbid delirium.

Case presentation. A 77-year-old woman with disorientation for one day came to Emergency Department with her family. She had no history of headaches, blurred vision, or seizures. However, she had a fever, did not want to eat for three days, and had a purulent decubitus ulcer. The patient was diagnosed with acute delirium syndrome, confirmed COVID-19 with sepsis, malnutrition, hypercoagulation, grade III decubitus ulcer, suspected dementia, immobilization, total dependence. The patient admitted to the isolation ward. The patient had meropenem $500 \mathrm{mg}$ every 12 hours, anticoagulants and favipiravir according to the dose and parenteral nutrition. Conclusion. Patients with COVID-19 who present with delirium, either as a primary symptom or presenting symptoms or signs, have a worse outcome. Delirium relationship with comorbid factors can increase mortality and morbidity in the elderly with COVID-19.
\end{abstract}

\section{Introduction}

The COVID-19 pandemic is still a problem all over the world. The total global COVID-19 confirmations in April 2021 were 131,528,621 cases with 2,857,978 deaths (CFR 2.2\%) in 222 affected countries and 190 local transmission countries. The case fatality rate in Indonesia is $2.7 \%$, with $1,542,516$ confirmed cases of covid 19 and 41,977 deaths in April 2021.1 Around $11.4 \%$ of confirmed cases of covid 19 are over 60 years of age. ${ }^{2}$ Typical COVID-19 symptoms such as fever (98\%), cough (76\%), dyspnea (55\%), and myalgia or fatigue (up to 44\%). A recent study found that the most common symptoms among the elderly group studied were shortness of breath (76\%), fever (52\%), and cough $(48 \%) \cdot{ }^{3}$ Some elderly patients show atypical symptoms such as delirium. Cohort study the latest of 817 patients aged with COVID-19, who came to the emergency room, 28\% experienced delirium between patients with delirium, 16\% experienced delirium as the main symptoms, and $37 \%$ had no symptoms or signs COVID-19 are typical, such as cough or fever. ${ }^{4}$

Delirium is a state of acute confusion characterized by an altered level of consciousness, disorientation, inattention, and other cognitive disturbances, commonly occurring in elderly patients and associated with a poor prognosis, including prolonged hospitalization and death. ${ }^{5}$ Delirium is common in the elderly with acute infection. ${ }^{6}$ Elderly with COVID-19 may present with atypical symptoms, including delirium and its complications. From several studies showed increased mortality and morbidity in the 
advanced group of age with COVID-19 with comorbidities. ${ }^{11}$ With this article, the authors intend to describe the relationship between delirium, COVID- 19 infection and other comorbidities.

\section{Case Presentation}

A 77-year-old woman with disorientation for one day came to Emergency Department with her family. She had no history of headaches, blurred vision, or seizures. However, she had a fever, did not want to eat for three days, and had a purulent decubitus ulcer. In addition, she had no history of shortness of breath, hoarseness, cough, anosmia or ageusia. Past medical history had a stroke three years ago with immobilization, total dependence and often forgetful. She has never been in contact with sick people or in contact with COVID-19 patients.

In Emergency Departments, she was in delirium. Examination of vital signs 140/50 mmHg, pulse 100 $\mathrm{x} /$ minute, respiration $25 \mathrm{x} /$ minute, oxygen saturation $97 \%$ with oxygen $3 \mathrm{~L}$ nasal cannula and temperature 39.C. On physical examination, BMI was 17.8 (malnutrition), chest examination revealed crackles at the bases of both lung fields and grade 3 decubitus ulcers on the pelvis. The chest X-ray showed bilateral pneumonia. Blood test results, $\mathrm{Hb} 9.0 \mathrm{~g} / \mathrm{dL}$, Leukocytes $14.330 / \mathrm{mm} 3$, urea $90 \mathrm{mg} / \mathrm{dL}$, creatinine $1.66 \mathrm{mg} / \mathrm{dL}$, Potassium $2.4 \mathrm{meq} / \mathrm{L}$, Albumin $1.8 \mathrm{gr} / \mathrm{dL}$, fibrinogen $542 \mathrm{mg} / \mathrm{dl}$, d-dimer $11.82 \mathrm{ug} / \mathrm{ml}$, normal urinalysis, positive RT PCR result with CT 36.8. Functional status examination using the Barthel index found total dependence, nutritional status assessment with MNA obtained malnutrition, cognitive function assessment using mini cog obtained a score of 0 indicating the possibility of cognitive impairment. However, the patient could not do MMSE due to delirium and frailty assessment with a 40I $=0.6$, which indicates a frail condition.

The patient was diagnosed with acute delirium syndrome, confirmed COVID-19 with sepsis, malnutrition, hypercoagulation, grade III decubitus ulcer, suspected dementia, immobilization, total dependence. The patient admitted to the isolation ward. The patient had meropenem 500 mg every 12 hours, anticoagulants and favipiravir according to the dose and parenteral nutrition. However, after two days of treatment, the patient worsened and passed away.

\section{Discussion}

The patient came to the Emergency Department with the chief complaint of disorientation for one day. According to the DSM-5 criteria, delirium, characterized by fluctuating disturbances of consciousness, inattention, and loss of consciousness, occurs in $20 \%$ of acutely hospitalized patients. ${ }^{12}$ International Classification of Diseases version 10 (ICD-10) describes delirium. An organic brain syndrome of non-specific aetiology characterized by disturbances of consciousness, attention, perception, thought, memory, psychomotor behaviour, emotion, and sleep. ${ }^{14}$ Delirium may manifest as hyperactivity, hypoactivity, or a mixture depending on the condition. ${ }^{8}$ Delirium is a clinical syndrome that is difficult to define clearly. Delirium has several terms such as a state of acute confusion, 'acute confusion', 'acute confusion in chronic', and 'acute brain failure' or 'acute encephalopathy'. ${ }^{10}$

Based on the history, the patient only complained of fever and did not want to eat three days before. COVID19 is mostly a respiratory disease. In the elderly, COVID-19 can present with atypical symptoms, including delirium and its complications. According to the World Health Organization, "change of consciousness/confusion" may be an early symptom of COVID-19, even before fever and cough. 8 With the increasing risk of death in the elderly with COVID-19, appropriate diagnostic protocols are needed to ensure early diagnosis and management. Delirium screening can use the 4AT. The 4AT had designed for use by health workers who are in the first contact with patients. This screening method is more straightforward, shorter and does not require special training to be used by anyone. ${ }^{7}$

In the elderly, viral infections such as COVID-19, fever, and hypoxemia can trigger delirium. Many factors cause delirium in Covid-19 patients. For example, lack of oxygen in the body or hypoxia, systemic diseases and systemic inflammation, 
excessive blood clotting disorders (coagulopathy), and viral infections directly to the brain. ${ }^{9}$

The cause of delirium in COVID-19 patients is likely multifactorial, including invasion of the central nervous system (CNS) by viruses. ${ }^{15}$ SARS-CoV-2 enters human cells via the angiotensin-converting enzyme (ACE2) receptor, expressed in various organs, including the brain. COVID-19-related respiratory failure and direct infection of the central nervous system by SARS-CoV2.9

In assessing cognitive function using mini cog, a score of 0 obtained where the patient indicated the possibility of cognitive impairment. Relationship of delirium with old age and neurological comorbidities, namely dementia. The clinical manifestations of superimposed delirium in dementia are sometimes difficult to distinguish from the usual symptoms of dementia, especially in clinical contexts, where health professionals do not have previous geriatric training, which can create diagnostic dilemmas that will affect management. In addition, the treatment of delirium overlapping with dementia in COVID-19 patients should carefully be evaluated. ${ }^{9}$

In the frailty assessment, the patient's condition was frailty. The elderly with frailty and COVID-19 are more likely to experience delirium than the elderly group who are not classified as frailty. This explains if the condition of frailty underlies the occurrence of delirium. In the elderly, frailty is a condition with increased susceptibility to stressors that can cause disease. Frailty conditions can worsen the illness and increase mortality in elderly patients with COVID-19 and delirium. ${ }^{13}$

This patient has several comorbidities such as malnutrition, hypercoagulability, post CVD, total rested immobilization. These conditions significantly affect morbidity, worse prognosis and mortality. ${ }^{13}$ The effect of nutrition on the body has been widely studied. In COVID-19 infection, the study of nutritional status plays an essential role in the immune system needed to deal with viral infections. Some conditions make individuals more susceptible and challenging to recover from viral infections, such as hypoalbuminemia, immobilization and reduce muscle mass. Several studies have shown the importance of maintaining a good nutritional status to boost the immune system. ${ }^{16}$

The brain has a high nutritional requirement, so that malnutrition can cause cognitive dysfunction in delirium. Several studies have found that $75 \%$ of patients with delirium are malnourished, suggesting that malnutrition contributes to delirium. Patients with malnutrition and delirium have a four times higher mortality rate in one month. ${ }^{17}$

\section{Conclusion}

Delirium is the most common symptom in the elderly with COVID-19. Patients with COVID-19 who present with delirium, either as a primary symptom or presenting symptoms or signs, have a worse outcome. Delirium relationship with comorbid factors can increase mortality and morbidity in the elderly with COVID-19.

\section{References}

1. Infeksi Emerging Kemkes. Situasi Terkini Perkembangan COVID 19 [Internet]. 2021. [cited 2021 June 21]. https://infeksiemerging.kemkes.go.id/situasi -infeksi-emerging/situasi-terkiniperkembangan-coronavirus-disease-covid-1907-april-2021

2. Satuan Tugas Penanganan COVID-19. Peta sebaran Gugus Tugas Percepatan Penanganan COVID-19 [Internet]. 2021 [cited 2021 June 21]. https://covid19.go.id/peta-sebaran.

3. Ohuabunwa, U., Turner, J. and Johnson, T. (2021) 'Atypical Presentations among Older Adults with COVID-19 Disease: A Need for Broadening the Differential Diagnosis', Gerontology and Geriatric Medicine. 2021 vol 7:1-4.

4. Kennedy M, Helfand BKI, Gou RY, et al. Delirium in Older Patients With COVID-19 Presenting to the Emergency Department. JAMA Netw Open. 2020;3(11):e2029540.

5. MacLullich AM, Hall RJ. Who understands delirium? Age Ageing. 2011;40(4):412-414.

6. Ahmad I, Rathore FA. Neurological manifestations and complications of COVID- 
19: a literature review. J Clin Neurosci. 2020;

77:8-12.

7. Emmerton D, Abdelhafiz A. Delirium in Older People with COVID-19: Clinical Scenario and Literature Review. SN Compr Clin Med. 2020;1-8.

8. Cipriani G, Danti S, Nuti A, Carlesi C, Lucetti C, Di Fiorino M. A complication of coronavirus disease 2019: delirium. Acta Neurol Belg. 2020;120(4):927-932.

9. Andrea Ticinesi, Nicoletta Cerundolo, Alberto Parise, Antonio Nouvenne, Beatrice Prati, Angela Guerra, Delirium in Covid-19: epidemiology and clinical correlations in a large group of patients admitted to an academic hospital. Aging Clin Exp Res. 2020; 32(10): 2159-2166.

10. Guideline 157: Risk reduction and management of delirium (2019) Publisher: Scottish Intercollegiate Guidelines Network (SIGN) [Internet]. 2021 [cited 2021 June 21]. https://www.sign.ac.uk/assets/sign 157.pdf.

11. Kang SJ, Jung SI. Age-Related Morbidity and Mortality among Patients with COVID-19. Infect Chemother. 2020;52(2):154-164.

12. American Psychiatric Association (2013) Diagnostic and statistical manual of mental disorders, 5th eds. American Psychiatric Association, Arlington, VA, USA

13. Zazzara MB, Penfold RS, Roberts AL, Lee KA, Dooley H, Sudre CH, Welch C, Bowyer RCE, Visconti A. Probable delirium is a presenting symptom of COVID-19 in frail, older adults: a cohort study of 322 hospitalized and 535 community-based older adults. Age Ageing. 2021 Jan 8;50(1):40-48.

14. World Health Organization (1993) The ICD-10 classification of mental and behavioural disorders: diagnostic criteria for research. WHO, Geneva

15. Li YC, Bai WZ, Hashikawa T. The neuroinvasive potential of SARS-CoV2 may play a role in the respiratory failure of COVID- 19 patients. J Med Virol. 2020;92:552-5.
16. Fernández-Quintela A, Milton-Laskibar I, Trepiana J, et al. Key Aspects in Nutritional Management of COVID-19 Patients. J Clin Med. 2020;9(8):2589. Published 2020 Aug 10.

17. Rosted E, Prokofieva T, Sanders S, Schultz M. Serious Consequences of Malnutrition and Delirium in Frail Older Patients. J Nutr Gerontol Geriatr. 2018 Apr-Jun;37(2):105-116 